\title{
Algumas possibilidades de cooperação dos leigos no munus regendi segundo a norma de direito
}

\author{
Some possibilities for cooperation of the laity in munus regendi \\ according to canonic law
}

Resumo: O objetivo deste artigo é o de apresentar algumas possibilidades de cooperação dos leigos no munus regendi segundo a normativa atual do Código de Direito Canônico de 1983. Para tanto, o texto está divido em duas grandes partes. A primeira trata dos princípios norteadores ainda necessários para uma cooperação eficaz do ponto de vista da igualdade, oportunidade

e corresponsabilidade dos fiéis leigos. A segunda parte aborda, de modo mais concreto, quais são os canais e os meios para essa cooperação seja em um nível mais amplo de Igreja Particular seja em nível mais restrito como o Paroquial. O texto não apresenta todos os ofícios e encargos que podem ser assumidos por

\section{Cristiano Parpinelli da Silva}

Abstract: The purpose of this article is to present some possibilities of cooperation of the laity in the munus regendi, according to the rules in force in the 1983 Code of Canon Law. Therefore, the text is divided into two main parts. The first deals with the guiding principles still necessary for effective cooperation from the point of view of equality, opportunity and coresponsibility of the lay faithful. The second part addresses, in a more concrete way, what are the channels and means for this cooperation, either at a broader level of the Particular Church or at a more restricted level, such as the Parish. The text does not present all the positions and duties that can be assumed

${ }^{1}$ É sacerdote, membro da Sociedade do Apostolado Católico (Padres e Irmãos Palotinos), Província Nossa Senhora Conquistadora, Santa Maria/RS. Obteve mestrado em Direito Canônico pela Pontifícia Universidade Lateranense de Roma, Itália (2020). Atualmente é doutorando da mesma universidade. Email: cparpinelli2@hotmail.com. 
leigos tampouco não irá esgotar o argumento, pois ainda é objeto de muita discussão. A conclusão procura evidenciar o quão importante é a presença e atuação dos leigos na vida da Igreja.

Palavras-chave: Cooperação; Leigos; Governo; Igreja; Direito. by the laity, nor will it exhaust the argument, as it is still the subject of much discussion. The conclusion seeks to show the importance of the presence and performance of the laity in the life of the Church.

Keywords: Cooperation; Laity; Government; Church; Canon Law.

\section{Introdução}

A participação dos leigos e o desempenho de seu papel na Igreja vêm sendo conteúdo de muitos debates, sobretudo, desde as grandes mudanças empreendidas no Concílio Vaticano II (1962-1965) As transformações da sociedade hodierna vêm exigindo mudanças nas estruturas da Igreja para melhor responder os inúmeros desafios existentes. No exercício da potestas regiminis, de direito divino e de direito humano, e diante das mudanças e desafios, a Igreja, na fidelidade ao Evangelho e sua missão, busca constantemente a prática de um justo equilíbrio jurídico-canônico evitando repetir problemas históricos decorridos no passado. Estes erros deturparam o verdadeiro sentido do exercício da potestas de governo na Igreja que, desde suas bases e finalidades, se diferencia do poder civil. O cân. 129, em seus dois parágrafos, evidencia os sujeitos para o exercício desta potestas abrindo a possibilidade de cooperação dos leigos. O presente artigo, sem pretender resolver a discussão ou exaurir todas as possibilidades de reflexão, busca evidenciar a possibilidade de cooperação dos leigos na potestas de regime da Igreja a partir da codificação canônica de 1983.

Em suma, o texto, como uma pesquisa bibliográfica, apontará prospectivas para possíveis debates baseando-se na doutrina canonística e autores e, enfim, deseja propiciar uma renovação de mentalidade para uma ampla participação efetiva de todos os 
batizados, de acordo com próprio estado e capacidade jurídica, na potestas de regime da Igreja e em sua vida e missão.

\section{Princípios norteadores para uma cooperação eficaz}

Na reflexão das possibilidades concretas de cooperação dos leigos no munus regendi da Igreja segundo a norma de direito, será abordado de modo não exaustivo, alguns princípios basilares para esta cooperação, tais como os princípios de igualdade e de oportunidade num primeiro momento $\mathrm{e}$ em seguida $\mathrm{o}$ princípio da corresponsabilidade da ação dos fiéis no governo eclesial e, precisamente, dos fiéis leigos.

\subsection{Princípios de Igualdade e de Oportunidade}

No que diz respeito ao princípio de Igualdade, pode-se afirmar que este é um conceito constitutivo da ideia de democracia dos modernos ordenamentos jurídicos. É um conceito que garante a posição de igualdade de todos diante da lei e evita a descriminação de raça, sexo, religião, de opinião política ou de condição social. Entre os elementos que formam o conceito, além do fato que o povo seja titular da soberania, existe a afirmação solene da capacidade de cada cidadão de ascender aos cargos públicos ou aos encargos eletivos, com direito de exigir do público poder a garantia de sua autonomia e o uso de seus direitos ${ }^{2}$.

O texto do Código de Direito Canônico possui uma concessão própria, um conceito próprio de igualdade como consequência específica da noção de fiel, da sua relação com o poder e aquilo que é próprio da comunidade eclesial. Tendo presente os elementos constitutivos do conceito de cidadania nos ordenamentos jurídicos modernos, a igualdade, do momento que acontece a incorporação a

\footnotetext{
${ }^{2}$ Cf. P. VALDRINI, Fedele, uguaglianza e organizzazione della Chiesa nel CIC del 1983, in A. SabetTa (CUR.), Studi di Diritto canonico in onore di S. E. Mons. Ignazio Sanna, Roma, 2012, p. 526.
} 
Cristo por meio do batismo, não deveria assimilar o fiel ao conceito de cidadão, o poder a uma representação e, em última análise, a Igreja ou a uma democracia. $\mathrm{O}$ conceito de igualdade ligado à figura jurídica de fiel é, de fato, específica. Se a palavra pode evocar, como na sociedade civil, a ideia de participação ou de representante, no âmbito eclesial é diferente. Fiel e potestas são duas noções que existem e envolvem um binômio fiel-cidadão na sociedade civil. O fiel, do ponto de vista do exercício da potestas não tem uma prioridade funcional, o qual o direito político ou o instrumento que garante a sua participação a definição de bens e valores da comunidade eclesial.

Assim, o princípio de igualdade que encontra uma raiz no batismo, deve existir junto ao princípio de origem divina e sacramental da estrutura hierárquica de Igreja, sem que o primeiro haja precedência na ordem do reconhecimento do poder. Sem dúvida, por manifestar em um texto jurídico esta concessão particular, o cân. 208 mantém ao mesmo tempo, o princípio de igualdade entre os fiéis na dignidade e, sobretudo, na ação, e a diferença dos munera que são confiados a pessoas segundo o seu estado jurídico ${ }^{3}$.

No que se refere ao princípio de Oportunidade está unido a praticidade e atuação da função, do ofício. Seria aplicado no "agir" do ofício. É interessante notar que a finalidade e a natureza própria do ofício não pode ser o único critério para o exercício da potestas de governo. Pois o específico da comunidade eclesial e o ofício a ser exercitado exigem, muitas vezes, o critério razoável da oportunidade. Para melhor responder e corresponder às próprias finalidades, a Igreja pode resevar alguns ofícios somente aos clérigos, no exercício pessoal da função, como também pode conferir a um exercício colegial do ofício em razão da oportunidade. Interessante questionar-se sobre a natureza do ofício. Contudo, se faz necessário entender o critério de cada reserva de ofício, ou ainda esclarecer se um ofício é reservado só aos clérigos pela natureza do mesmo ofício ou por motivo de oportunidade. Muitas vezes, o exercício de certa potestas regiminis

${ }^{3}$ Cf. Ibid., p. 528. 
feita colegialmente ou com uma natureza muito mais técnico e profissional seria mais oportuna e relevante no momento ${ }^{4}$.

\subsection{Princípio de corresponsabilidade dos fiéis leigos no governo eclesial}

Embora o termo corresponsabilidade não apareça na normativa canônica atual, o princípio de corresponsabilidade dos fiéis batizados no governo eclesial é uma das condições mais que necessárias para uma cooperação efetiva e concreta do leigo na potestas de governo. A corresponsabilidade deve ser entendida no interno da dinâmica relação entre sacerdócio comum dos fiéis e sacerdócio ministerial. O termo corresponsabilidade é uma das consequências da eclesiologia conciliar do Vaticano II que afirmava a participação dos fiéis na tria munera de Cristo $^{5}$ sendo o sacerdócio comum e o ministerial como dois modos distintos de participação a um único sacerdócio de Cristo. O princípio da corresponsabilidade cabe àqueles que exercem a potestas capital como também ao cristão batizado não ordenado. Sobre a corresponsabilidade a todos os membros do Povo de Deus, já afirmava Bento XVI:

É necessário, ao mesmo tempo, melhorar a orientação pastoral, de modo que, no respeito das vocações e dos papéis dos consagrados e dos leigos, se promova gradualmente a corresponsabilidade do conjunto de todos os membros do Povo de Deus. Isto exige uma mudança de mentalidade no que diz respeito particularmente aos leigos, passando de considerá-los "colaboradores" do clero ao reconhecê-los realmente "corresponsáveis" do ser e do agir da Igreja,

\footnotetext{
${ }^{4}$ Cf. E. Kouveglo, I fedeli laici e l'esercizio della potestà nella Chiesa. Status quaestionis e ricerca di una chiave funzionale di lettura, in Apolinaris LXXXX, 1, Città del Vaticano, 2017, p. 222-223.

${ }^{5}$ Cf. CONCILIUM OECUMENICUM VATICANUM II, Constitutio dogmatica de Ecclesia: Lumen Gentium, in AAS, LVII (1965), 5-71, n. 10.
} 
favorecendo a consolidação de um laicato maduro e comprometido ${ }^{6}$.

A corresponsabilidade do laicato não significa a isenção da responsabilidade e corresponsabilidade dos clérigos que exercem a funções de ofícios capitais, por outro lado, não se quer uma clericalização dos fiéis leigos, mas uma atuação na justa medida e no espírito de colaboração e cooperação. O termo remete a uma ideia de participação em conjunto, sobre o mesmo plano das diversas posições jurídicas dos fiéis à responsabilidade da comunidade hierárquica ${ }^{7}$.

A corresponsabilidade, desta forma, cabe a todos os batizados no exercício da missão eclesial. E com isso, é possível definir dois tipos de corresponsabilidade: uma derivante da condição jurídica do fiel batizado e outra que deriva da condição jurídica do ministro ordenado. A partir disso, seria possível afirmar a existência de uma corresponsabilidade participada sem nenhuma supervalorização do modo como exercê-la. Pois, em se tratando de corresponsabilidade pastoral, a cura pastoral é uma atividade reservada ao titular do ofício capital da comunidade, ao pároco ou ao bispo diocesano. E os fiéis que receberam a ordem sacra estão hábeis para esta função ${ }^{8}$. Naquilo que diz respeito a potestas de governo, segundo Arienzo, a corresponsabilidade do exercício da potestas poderia ser participada ${ }^{9}$.

\footnotetext{
${ }^{6}$ Cf. Benedetto XVI, Apertura del convegno pastorale della diocesi di Roma sul tema: Appartenenza ecclesiale e corresponsabilità pastorale Basilica di San Giovanni in Laterano, Martedì, 26 maggio 2009.

${ }^{7} \mathrm{M}$. D'ARIENZO, Il concetto giuridico di responsabilità: rilevanza e funzione nel Diritto Canonico, Diritto e Religione, n. 24, Cosenza, 212, p. 177.

${ }^{8}$ A expressão cura pastoral aplicada aos ofícios maiores da comunidade hierárquica é reservada aos cargos de pastores da comunidade, enquanto se exercita na comunidade uma função específica fundada sobre a consagração recebida na ordenação. Recebe a possibilidade de exercitar a potestas tria munera Persona Christi Capitis (cf. IOANnes PAulus PP. II, Codex Iuris Canonici, auctoritate Ioannis Pauli PP. II promulgatus, in $A A S$, LXXV (1983), Pars II, 1-320. cânn. 1008; 1009) (Ibid., p. 181). 
Vale ressaltar que a normativa canônica de 1983 prevê, de uma parte, a participação dos fiéis segundo o próprio estado, de outra parte, não consente que o exercício da responsabilidade seja dependente exclusivamente das pessoas sem que seja reconhecido o estatuto específico, ou ainda, a responsabilidade, a titularidade dos ofícios como cabeça da comunidade hierárquica. Estes são titulares pessoalmente da cura pastoral. Por isso, no Código não se usam as palavras "corresponsabidade", mas também as palavras "colaboração" e "cooperação". Uma articulação específica entre os dois modos de assumirem a responsabilidade adquirida no batismo e na ordenação sacerdotal e que são expressão da tradição canonística reavaliada pelo Concílio Vaticano II $^{10}$.

E ainda, nesta linha de pensamento, colaboração e cooperação pressupõem uma relação assimétrica entre quem é titular de uma competência e quem colabora em uma posição de subordinação e de acessoria. Infelizmente ainda corre-se o risco de reduzir o apostolado dos leigos sobre a base do sacerdócio comum a uma mera colaboração adjunta, a uma suplência. Seria atribuir uma medida de valor a ambas as funções na missão da Igreja e diminuir o papel dos leigos a uma função marginal ${ }^{11}$. Seria uma relação desequilibrada tendo os ministros sacros

\footnotetext{
${ }^{9}$ Cf. M. D’ARIENZO, Il concetto giuridico di responsabilità: rilevanza e funzione nel Diritto Canonico, Diritto e Religione, n. 24, Cosenza, 212, p. 178.

${ }^{10} \mathrm{O}$ código usa a palavra partecipação no cân. $517 \S 2$ que dá ao bispo diocesano, em alguns casos, a possibilidade de confiar o exercício da cura pastoral de uma paróquia a fiéis leigos orientados por um sacerdote dotado dos poderes e das faculdades de pároco. $\mathrm{O}$ cânon utiliza a expressão participação ao exercício da cura pastoral e confiada ao moderador parte daquele exercício. A expressão participam é usada também no cân. $536 \S 1$ que diz respeito ao Conselho Pastoral Paroquial (Cf. A. MONTAN, Responsabilità ecclesiale, corresponsabilità e rappresentanza, in $\mathrm{P}$. GHERRI (a cura di) Responsabilità ecclesiale, corresponsabilità e rappresentanza: atti della giornata canonistica interdisciplinare, Città di Vaticano, 2010, p.10).

${ }^{11}$ IOANNES PAULUS PP. II, Adhortatio apostolica postsynodalis: Christifideles Laici, in AAS, LXXXI (1989), 393-521, n. 23; CONGREGATIO PRO CleRICIS ET ALIÆ, Instructio interdicasterialis de quibusdam quæstionibus circa fidelium laicorum cooperationem sacerdotum ministerium spectantem: Ecclesice de mysterio, in AAS, LXXXIX (1997), 852-877, n.4.
} 
em uma posição de preeminência em relação aos leigos que devem ser subordinados. Seja porque a relação ou correlação se desenvolva somente sob a esfera de fazer e não na esfera do ser, ou ainda, os leigos desenvolvam ações de operatividade, mas a sua participação não é considerada necessária e imprescindível para a realização do ser Igreja $^{12}$. Neste sentido, a corresponsabilidade dá suporte a cooperação no que diz respeito ao ser e ao agir na potestas eclesial.

A responsabilidade implica a divisão de competências com outros sujeitos. Se é responsável enquanto se é titular próprio das determinações e atribuições, também se o objeto pode ser comum às atribuições dos outros, e se é titular porque se é capaz de desenvolver aquelas atribuições em modo correto e de acordo a sua natureza, enquanto se é recebida a idônea habilidade. Por isso, se pode ser chamado a ser consciente, no próprio âmbito e segundo as próprias capacidades, se é realizada a missão comum ${ }^{13}$.

A corresponsabilidade pressupõe uma relação de igualdade entre os sujeitos que dividem igual competência, enquanto todos participam com a mesma legitimação a realização de um objetivo comum. Além disso, igualdade de legitimação não significa uniformidade de ações, porque cada um contribui ao seu próprio modo, segundo a própria vocação. Ministros ordenados e leigos, enquanto batizados, participam do único sacerdócio de Cristo na missão da Igreja.

Com isso, a relação entre sacerdócio comum e sacerdócio ministerial não pode ser compreendido como uma absorção de um em detrimento ao outro, mas sim numa autêntica relação de reciprocidade e complementaridade não somente no agir, mas no ser da vida da Igreja. Os munera desempenhados por leigos no âmbito do sacerdócio

\footnotetext{
${ }^{12} \mathrm{Cf}$. A. Montan, Ministeria, munera, officia. I laici titolari di uffici e di ministeri (cann. 228, 230, 274): precisazioni terminologiche, in. AA.V.V., Il governo nel servizio della comunione ecclesiale, Quaderno della Mendola 8, Milano, 2000, p. 102. ${ }^{13}$ Cf. I. ZUANAZZI, La corresponsabilità dei fedeli laici nel governo ecclesiale, in. AA.V.V., Il governo nel servizio della comunione ecclesiale, Quaderno della Mendola 25, Milano, 2016, p. 128.
} 
comum são essenciais para o exercício dos ministérios hierárquicos dos clérigos. No exercício destes ministérios, leigos e clérigos desenvolvem um serviço mútuo que é igualmente necessário para o crescimento da comunidade eclesial.

Desta forma, o princípio de corresponsabilidade é indispensável no desenvolvimento de uma cooperação efetiva e eficaz no exercício da potestas de governo da Igreja. A valorização da participação do leigo na missão da Igreja, portanto, não é realizado atribuindo papéis de mera colaboração ao ministério da hierarquia, nem criando estruturas alternativas de apostolado modeladas no modelo clerical. É necessário levar a sério a relação de complementaridade entre o sacerdócio comum e o ministerial e reconhecer e promover a contribuição apropriada e original que os leigos podem oferecer para a edificação do povo de Deus e, ao mesmo tempo, um laicato comprometido e atuante ${ }^{14}$.

\section{Cooperação dos leigos}

Nesta parte do texto será abordada a possibilidade de cooperação dos leigos na potestas de governo da Igreja. Primeiramente, será refletido sobre os leigos e sua participação no exercício de poder na Potestas Colegial, e em seguida, será abordada a cooperação dos leigos em alguns órgãos colegiados consultivos, algumas funções e ministérios tanto a nível paroquial (Conselho Pastoral e Conselho Econômico) como a nível diocesano (Conselho Pastoral, Conselho Econômico e Econômo Diocesano). E, por último, de modo mais efetivo, a cooperação dos leigos como Juiz em um Tribunal colegial e algumas das funções que podem ser exercidas por um leigo em um tribunal eclesiástico.

${ }^{14}$ I. ZUANAZZI, La corresponsabilità dei fedeli laici nel governo ecclesiale, in AA.V.V., Il governo nel servizio della comunione ecclesiale, Quaderno della Mendola 25, Milano, 2016, p. 129. 


\subsection{Os leigos e a Potestas Colegial}

Deve-se levar em consideração que o princípio colegial é parte integrante da constituição da Igreja $^{15}$, pois entre seus elementos básicos existem aspectos importantes como a colegialidade episcopal ${ }^{16}$ ou também a realização da cooperação do presbitério com o bispo ${ }^{17}$. Com efeito, o vínculo de comunhão que existe entre os bispos justifica a canonicidade de instituições sinodais que agrupam aos bispos para o serviço da Igreja Universal em comunhão com o Papa (concílio ecumênico, sínodo dos bispos, colégio cardinalício, colégios da Cúria Roma) e o das Igrejas particulares nos distintos países (concílios particulares, conferências episcopais) ${ }^{18}$.

Ademais, o direito canônico contempla uma ampla variedade de entidades colegiais em todos os níveis do governo como, também, é possível fazer uma classificação dos colégios segundo a existência ou não da personalidade jurídica; se a convocação é periódica (por exemplo, conferências episcopais), ou solene e ocasional (por exemplo, conselhos); dependendo se exercem ou não o potestas de

\footnotetext{
${ }^{15}$ As diversas manifestações do princípio colegial estão presentes na normativa del CIC de 1983, segundo três termos usados pelo legislador: collegium, collegalis e collegialiter (Cf. A. VIANA, El gobierno colegial en la Iglesia, in Ius Canonicum 36, 1996, p. 471; IDEM, Colegio, In Diccionario General de Derecho Canònico, ed. J. OTADUY - A. VIANA - J. SEDANO, II, 2012, p. 215-225).

${ }^{16}$ Para aprofundamento do tema $\mathrm{cf}$. A. MonTAN, Collegialità e sinodalità nella vita della Chiesa: aspetti giuridici con riferimento alla Chiesa Particolare, in. AA.V.V., Il governo nel servizio della comunione ecclesiale, Quaderno della Mendola 25, Milano, 2016, p. 31-58.

${ }^{17}$ Como recorda Pastor Bonus: a constitução hierárquica da Igreja foi dotada por Jesus Cristo com uma natureza « colegial e ao mesmo tempo primacial », como que o Senhor, segundo as palavras tomadas de Lumen gentium n. 19: instituiu os Apóstolos à maneira de colégio ou grupo estável, ao qual prepôs Pedro escolhido dentre os mesmos (IOANNES PAUlus PP. II, Constitutio apostolica de Romana Curia: Pastor Bonus, in AAS, LXXX (1988), 841-934. n. 2) Cf. ConCILIUM OeCUMENICUM VATICANUM II, Constitutio dogmatica de Ecclesia: Lumen Gentium, in $A A S$, LVII (1965), 5-71, n.19.

${ }^{18}$ Cf. cânn. 337-314, 342-348, 349-359, 439-446, 447-459.
} 
regime e outras. Da mesma forma, os regulamentos sobre institutos religiosos baseiam-se em extensa experiência histórica de governo colegial. O Código promove o estabelecimento de vários conselhos para a ajuda dos superiores dos institutos religiosos ${ }^{19}$. Segundo Viana

[...] o governo na Igreja não é meramente uma atividade individual, não é apenas reservada exclusivamente nas suas manifestações aos ofícios capitais. O princípio pessoal ou capital, que se poderia chamar de monárquico, é completo pelo princípio colegial; de maneira que participam na direção da vida social do Povo de Deus diversos sujeitos coletivos em todos os níveis de organização de governo: universal, interdiocesano, diocesano. A colegialidade é, neste sentido, um verdadeiro critério informador da vida jurídica da Igreja, embora sempre de maneira complementaria com as exigências constitucionais derivadas do princípio capital, fundado na sucessão apostólica ${ }^{20}$.

E se pode definir canonicamente o colégio como uma instituição, um ofício, cuja titularidade é compartilhada por um grupo (coetus) de pessoas que contribuem com o seu voto a formação da vontade colegial segundo os requisitos e efeitos estabelecidos pelo direito. O cân. $115 \S 2$ estabelece estes requisitos como aspectos básicos dos colégios estabelecidos na organização oficial da Igreja. Aspectos estes que os diferenciam de outras possíveis manifestações e atuações coletivas. Concretamente não é elemento necessário a igualdade restrita de direitos entre os membros, de maneira que todos ocupem a mesma posição jurídica. Com efeito, cada membro tem direito a intervir na formação da vontade colegial, mas pode ser diferente ao alcance jurídico do seu voto consultivo ou deliberativo. A normativa canônica, ao tratar das pessoas jurídicas colegiais,

\footnotetext{
${ }^{19}$ Cf. cânn. 627, 631 e 632.

${ }^{20}$ Cf. A. ViAnA, El gobierno colegial en la Iglesia, in Ius Canonicum 36, 1996, p. 465-466.
} 
reconhece que os membros determinam a atividade colegial "com direitos iguais ou não"21.

Mas, além da diversidade terminológica e das possíveis classificações, todas as instituições cumprem suas características próprias no que se refere a pluralidade de membros colegiais, ao procedimento de formação e determinação da vontade colegial mediante votos, a existência de uma estrutura interna e finalmente um regime jurídico específico que determina a posição dos colégios na organização pública da Igreja. Bem como é de se considerar que existam variados fundamentos teológicos para dar razão a todas as atividades colegiais reconhecidas pelo direito, como por exemplo, os fundamentos para um conselho pastoral não é o mesmo para um conselho presbiteral ou para um conselho econômico ${ }^{22}$.

Nesta mesma linha, e mais especificamente, a colegialidade expressa também em sua relação com a constituição eclesiástica por meio de colégios consultivos para realizar estavelmente a cooperação do presbitério com o bispo na Igreja particular. Estes são o conselho presbiteral, o colégio de consultores e o cabido de cônegos ${ }^{23}$. Mas o princípio colegial alcança mais além. Serve também para expressar a corresponsabilidade e participação dos fiéis na missão de toda a Igreja ${ }^{24}$.

Como nas Igrejas Particulares (Conselho Pastoral, por exemplo), os critérios de corresponsabilidade e participação afetam também a vida da Igreja universal. Para tanto, a Cúria Romana como estrutura de governo auxiliar do Papa, adota formas colegiais de atuação (dicastérios e tribunais da Santa Sé) que admitem a atuação de cardeais, bispos outros fiéis ${ }^{25}$. Nestes casos devem-se levar sempre em

\footnotetext{
${ }^{21}$ Cf. Ibid., p. 486.

${ }^{22}$ Cf. Ibid., p. 487.

${ }^{23}$ Cf. Concilium Oecumenicum Vaticanum II, Decretum de pastorali Episcoporum munere in Ecclesia: Christus Dominus, in AAS, LVIII (1966), 673-701, n. 11.

${ }^{24}$ A.VIANA El problema de la participación de los laicos en la potestad de régimen. Dos vías de solución, in Ius Canonicum, vol 54, 2014, p. 630.

${ }^{25}$ Com a promulgação da Constituição Apostólica Pastor Bonus de 28 de junho de 1988 se iniciou o sexto período da história da Curia Romana. A preparação do texto
} 
conta os critérios da normativa canônica para o exercício da potestas colegial bem como o significado da vontade colegial ${ }^{26}$.

Com efeito, a vontade colegial formada mediante o voto dos membros se atribui ao colégio como instituição e não a cada um dos membros. Estes podem dar sua opinião e votar com os demais na fase de preparação da vontade colegial; mas quando esta se formou, normalmente mediante o sistema da maioria absoluta ${ }^{27}$, o ato ou vontade colegial fica objetivada em si mesma, e pode não coincidir com a vontade de cada um dos membros do colégio ${ }^{28}$. A vontade ou ato colegial, portanto, não pode ser atribuída aos membros individualmente considerados, mas ao colégio como sujeito unitário, uma vez que se tem conseguido determinar essa vontade colegial mediante o procedimento legítimo de maiorias ou através de acordos adotados por consenso ${ }^{29}$.

da constituição foi um longo período porque João Paulo II queria submeter os trabalhos seja a Comissão de preparação da reforma seja aos diversos consistórios de cardeais. A Constituição introduz uma melhor classificação dos diversos organismos e de suas competências jurídicas distinguindo os pontícificos institutos e os dicastérios (Cf. P. VALDRINI, Comunità, persona, governo. Lezioni sui i libri I e II del CIC 1983, Città del Vaticano, 2013, p. 140-144).

${ }^{26}$ A.VIANA El problema de la participación de los laicos en la potestad de régimen. Dos vías de solución, in Ius Canonicum, vol 54, 2014, p. 631.

${ }^{27}$ Cf. cânn. 115 §2 e 119 .

${ }^{28}$ A.VIANA El problema de la participación de los laicos en la potestad de régimen. Dos vías de solución, in Ius Canonicum, vol 54, 2014, p. 631.

${ }^{29}$ A vontade colegiada, uma vez legitimamente formada, é imposta e vinculada a todos os membros do colégio; para que o direito não proteja opiniões que não estejam de acordo com o conteúdo da decisão final da maioria. Em alguns sistemas jurídicos, se admite a técnica do voto privado, pela qual o membro dissidente pode publicar sua opinião contrária ao acordo final do colégio, embora esteja vinculado por ele. Para a atual normativa canônica, o cân. $1609 \S 4$ permite que o juiz que não deseja aderir à decisão dos demais e possa exigir que, se houver recurso, suas opiniões sejam transmitidas ao tribunal superior (Cf. A.VIANA El problema de la participación de los laicos en la potestad de régimen. Dos vías de solución, in Ius Canonicum, vol 54, 2014, p. 632). 
Com efeito, a organização eclesiástica consta de colégios nos quais os membros participam por ser titulares de um ofício com potestas de regime. E também alguns casos os quais os membros ficam adscritos sobre a base de requisitos de idoneidade distinto da titularidade de um ofício com potestas (ordinária).

Um exemplo do primeiro tipo de colégios é a conferência episcopal, já que é um colégio no qual os membros (os bispos diocesanos e equiparados) são já titulares de potestas ordinária (cf. cân. 450§1). E um exemplo de colégios nos quais os membros não são adscritos em virtude da titularidade de um ofício com potestas são os discatérios da Cúria Romana, já que nesses colégios participam fiéis escolhidos de diversas partes do mundo, entre os quais se contam os bispos diocesanos, mas também cardeais, bispos e outros fiéis que não são nomeados com base no poder que exercem $^{30}$, mas em sua capacidade de ajudar a Santa Sé, especialmente por sua perícia e experiência nos assuntos tratados pelo dicastério ${ }^{31}$.

Certamente, nos colégios de organização eclesiástica a questão do sacramento de ordem como requisito de titularidade do ofício não se expressa da mesma maneira que quando se trata de ofícios unipessoais, já que nestes tem uma dimensão de representação pessoal que não se dá no caso das pessoas jurídicas ou entes colegiais ${ }^{32}$. Por

${ }^{30}$ Cf. Ionnnes Paulus PP II Constitutio Apostolica de Romana Curia Pastor Bonus, in $A A S$ 80, 1988, n. 7.

${ }^{31}$ Cf. A.Viana El problema de la participación de los laicos en la potestad de régimen. Dos vías de solución, in Ius Canonicum, vol 54, 2014, p. 633.

${ }^{32}$ Se explica assim, por exemplo, que não deva ser pároco uma pessoa jurídica (cf. cân $520 § 1$ ), já que na paróquia é necessária uma representação pessoal do Senhor a frente da comunidade, que só pode ser refletida por uma pessoa física, sobretudo, quando se pensa na centralidade da celebração eucarística para a vida paroquial. Ou ainda, por exemplo, as decisões legislativas de um concílio particular (cân. 445) se atribuem ao mesmo concílio como instituição e não aos bispos membros individualmente considerados (cf. A.VIANA El problema de la participación de los laicos en la 
outra parte, a constatação evidente de que as instituições colegiais de organização eclesiástica não podem receber a potestas de Ordem Sacra, pois esta é conferida mediante o sacramento e os sacramentos somente podem ser recebidos pelas pessoas físicas. Por sua vez, os colégios se distinguem como tais dos membros que os compõem ${ }^{33}$.

É de se ressaltar também que a capacidade, a escolha e a nomeação dos membros resultam requisitos prévios para a incorporação ao colégio, mas a atividade colegial tem consistência própria no direito. O aprofundamento do princípio jurídico da colegialidade é uma maneira de resolver o embate da participação dos leigos na potestas regiminis. Nesta lógica, o colégio é titular da potestas somente se tem seus membros titulares. A nomeação de leigos como juízes de um tribunal colegiado $^{34}$ segundo a norma canônica levar-se-ia em consideração a vontade colegial, e não a potestas individual de um juiz.

E não se pode dizer que o colégio teria a potestas, mas não o teriam os juízes, já que se trata precisamente de um colégio de juízes, um tribunal. No caso da participação dos leigos na potestas de governo como juiz de um tribunal, este poder seria do colégio e dos juízes individualmente. Neste sentido, se pode assinalar que a doutrina colegial é relevante para solucionar a problemática do poder exercido pelos leigos na potestas regiminis, ao menos para evitar falsos problemas que dizem respeito, por exemplo, a constituição dos dicastérios, secretarias e outros ofícios da Cúria Romana ${ }^{35}$.

Por esses motivos, portanto, em teoria é possível que fiéis que não receberam o sacramento de ordem exerçam a potestas de regime unidos a outros fiéis que sejam clérigos e participem no mesmo colégio da organização eclesiástica. Isso pode acontecer em alguns dicastérios

potestad de régimen. Dos vías de solución, in Ius Canonicum, vol 54, 2014, p. 633).

${ }^{33} \mathrm{Cf}$. A.VIANA El problema de la participación de los laicos en la potestad de régimen. Dos vías de solución, in Ius Canonicum, vol 54, 2014, p. 633.

${ }^{34}$ Cf. cân. $1421 \S 2$.

${ }^{35}$ A.VIANA El problema de la participación de los laicos en la potestad de régimen. Dos vías de solución, in Ius Canonicum, vol 54, 2014, p. 632. 
da Cúria Romana, a exceção dos que estão estritamente ligados ao Sacramento da Ordem. Clérigos e leigos podem ser chamados a cooperar nos colégios da organização eclesiástica de acordo com critérios de escolha, nomeações e funções previstas para os membros pelas normas jurídicas de cada ente colegial da Igreja. Segundo esses requisitos, os fiéis recebem uma missio canonica que os inscreve ao colégio para cooperar como os demais nas tarefas previstas.

\subsection{A efetiva cooperação dos leigos em algumas funções e ministérios}

Especificamente de modo mais concreto é possível evidenciar algumas funções e ministérios que podem ser assumidos por leigos. São ainda mecanismos de participação e representação que podem levar a uma possível cooperação na potestas de governo.

Vale lembrar que com as mudanças realizadas pós - Concílio Vaticano II foi acentuado que todos os fiéis da Igreja, não apenas os ordenados, participam e são titulares e corresponsáveis da missão evangelizadora da Igreja. Nesta missão é inserida a tríplice função de ensinar (munus docendi) ${ }^{36}$, santificar (munus sanctificandi) $)^{37} \mathrm{e}$ de governar (munus regendi) ${ }^{38}$ e cabe aos batizados, conforme sua

\footnotetext{
${ }^{36}$ No múnus docendi ganha destaque o cân. 229 com o direito-dever a formação na doutrina cristã $(§ 1)$; o direito de estudar as ciências sagradas e a obter graus acadêmicos em universidade ou faculdades eclesiásticas e nos institutos de ciências religiosas (§2) e, obtida esta formação, ter o mandato de ensinar as ciências sagradas (§3).

37 Com a devida autorização do Ordinário Local, seguindo as prescrições e orientações da Conferência Episcopal Local, na ausência de uma ministro ordenado e conforme a necessidade, como munus sanctificandi os leigos podem: ser designados como ministro extraordinários do sacramento do Batismo (cân. 861§2), serem ministros extraordinários da Sagrada Comunhão (cân. 910§2), serem testemunhas qualificadas na assistência de matrimônios (cân. 112), presidir as orações litúrgicas e exercer o ministério da Palavra como também presidir exéquias e ritos funerais (cân. 230§3).

${ }^{38}$ No munus regendi, os leigos podem em função judicial, serem nomeados a desempanhar todos os ofícios e cargos em tribunais eclesiásticos, com excessão o de
} 
condição, desempenhá-la. E pode ser vista que a renovação eclesial foi dando lugar a uma progressiva desconstrução, não apenas terminológica, mas passando-se da clássica munus/potestas de jurisdição (potestas iurisdictionis) a uma potestas de governo (potestas regiminis). E ainda uma ampliação do conceito de munus regendi ou função de governo ao conceito de ministerialidade que reflete a dimensão de serviço, própria de todo o poder ou função na Igreja nos dias atuais. A ministerialidade laical, neste mesmo sentido, significa não apenas participação dos leigos no munus regendi, mas entra no âmbito da corresponsabilidade ${ }^{39}$.

Existem alguns ofícios e funções unicamente reservadas àqueles que receberam o sacramento da ordem. É o caso dos ofícios que comportam a plena cura, o exercício pastoral, o pleno cuidado das almas para o cumprimento da tarefa daqueles que possuem a ordem sacra. É o caso, por exemplo, daqueles que possuem o ofício pastoral de estabilidade de uma comunidade hierárquica como é o caso do bispo diocesano ou de pároco em uma paróquia. Tais ofícios não poderiam ser exercitados validamente se atribuídos a quem não possui o Sacramento da Ordem Sacra. Diz o cânon: "O ofício que implica plena cura das almas, para cujo desempenho se requer o exercício da ordem sacerdotal, não pode ser conferido validamente a quem ainda não foi promovido ao sacerdócio" 40 .

Pode-se afirmar, contudo, que a doutrina canonista pósconciliar busca superar certo clericalismo do Código de 1917. O

Vigário Judicial e Vigário Judicial Adjunto (cân.1420§4) e o de Juiz único (cân.1421§1). Podem ser nomeados para os cargos de Secretário Geral ou Moderador da Chancelaria do Tribunal, notário (cân.1437), assessor do Juiz único (cân.1424), auditor não juiz (cân.1428) e Defensor de vínculo e Promotor de Justiça (cân.1435). E em função executiva as que mais se descatam são Chanceler e Notário da Cúria (cân. 482-484), Ecônomo diocesano (cân. 494), Censor de livros (cân. 830§1) e Administrador de pessoas jurídicas públicas eclesiásticas (cânn. 1279-1280).

${ }^{39}$ Cf. C. P. GARcía. Sinodalidad y laicato. Corresponsabilidad y participación de los laicos en la vocación sinodal de la Iglesia, in Ius Canonicum, vol. 59, 2019, p. 5.

${ }^{40} \mathrm{Cf}$. cân. 150. 
Código de 1983 toma como ponto de partida os direitos comuns de todos os fiéis, independentemente de sua condição. E depois reconhece os deveres/direitos próprios e específicos dos fiéis leigos ${ }^{41}$. A codificação atual acentua não uma oposição ou divisão, mas apresenta uma dialética de comunhão e participação, uma dialética de complementaridade e não de contraposição. Entre direitos e deveres que correspondem a todos os fiéis batizados, independente de sua condição laical ou clerical, existem direitos muito significativos.

[...] direito-dever de iniciativa apostólica (c.216) e o direitodever de trabalhar na evangelização (c. 211), muito vinculado com a dimensão missionária da Igreja. Este direito-dever vem reiterado - já especificamente referido aos leigos - no c. 225, que os reconhece tanto individual como associadamente, se bem faz uma especial referência ao dever de aperfeiçoar a ordem temporal com o espírito evangélico, enquanto que em c. 227 reconhece o direito dos leigos a liberdade de atuação nos assuntos terrenos, e o c. 226 , em relação com a importante função eclesial da família, se refere ao direito-dever de edificar o Povo de Deus através o matrimônio e a família, assim como o direito-dever de educar os filhos ${ }^{42}$.

A dialética direitos-deveres dos fiéis leigos deve levar a uma consciência mais corresponsável que tem suas origens no sacramento do batismo. Da parte da Igreja supõe o reconhecimento da responsabilidade e autonomia dos fiéis em sua relação com os pastores. Ao reconhecer o direito e incluso o dever dos fiéis, segundo o conhecimento, competência e prestígio, o legislador, de modo normativo, põe a corresponsabilidade dos leigos em sua participação na tríplice missão de Cristo.

\footnotetext{
${ }^{41}$ Direitos comuns de todos os fiéis cf. cânn. 208-223; deveres/direitos dos fiéis leigos cf. cânn. 224-231.

${ }^{42}$ Cf. C.P.GARCíA. Sinodalidad y laicato. Corresponsabilidad y participación de los laicos en la vocación sinodal de la Iglesia, in Ius Canonicum, vol. 59, 2019, p. 8).
} 
Entre estes direitos, o direito a opinião, por exemplo, é uma expressão da participação corresponsável e, neste sentido, se reconhece expressamente a capacidade dos leigos a assessorar aos pastores e tomar parte nos conselhos instituídos ${ }^{43}$. Consequentemente, o ordenamento canônico abre a porta a uma significativa participação dos leigos em órgãos colegiados de governo ${ }^{44}$. Em âmbito diocesano

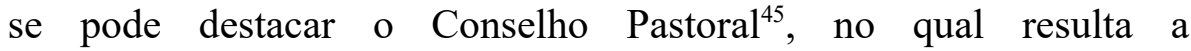
obrigatoriedade inclusão dos $\operatorname{leigos}^{46}$ e o Conselho de Assuntos Econômicos ${ }^{47}$ que gozam de importantes atribuições. Em âmbito paroquial $^{48}$, existem o Conselho Pastora ${ }^{49}$ e o Conselho de Assuntos Econômicos ${ }^{50}$ como meios de cooperação em torno ao pároco em sua forma jurídica ${ }^{51}$.

\footnotetext{
${ }^{43}$ Cf. cânn. $212 \S 2 ; 228 \S 2$.

${ }^{44} \mathrm{Cf}$. Trata-se de uma novidade institucional vivamente recomendada pelo Concílio Vaticano II CONCILIUM OeCumenicum VATICANUM II, Decretum de pastorali Episcoporum munere in Ecclesia: Christus Dominus, in $A A S$, LVIII (1966), 673-701, n. 27. Idem, Concilium OeCumenicum VaticANum II, Decretum de Presbyterorum ministerio et vita: Presbyterorum Ordinis, in AAS, LVIII (1966), 991-1024, n. 7. ${ }^{45}$ Cf. cân. 511-514.

${ }^{46}$ O Motu Proprio Ecclesiae Sanctae esclarece ainda mais a sua função como a de estudar e avaliar as atividades pastorais na diocese e de fazer sugestões práticas sobre futuros programas no ministério pastoral. Cf. PAULUS PP VI, Ecclesiae Sanctae, in $A A S$ 58, 1966, n. 16 e 17.

${ }^{47}$ Cf. cân. 492; 1282. Dado a sua importância, o ditto conselho deverá ser interpelado conjuntamente ao Colégio de Consultores e assim entra na potestas de governo do bispo diocesano, in regimine. É um orgão consultivo, e suas decisões assumem, às vezes, caráter vinculante (Cf. P. VALDRINI, Comunità, persona, governo. Lezioni sui i libri I e II del CIC 1983, Città del Vaticano, 2013, p. 81).

${ }^{48}$ Regolamentada nos cânn. 511-514.

${ }^{49}$ Cf. cân. 536.

${ }^{50}$ Cf. cân. 537. A função do Conselho Econômico da Paróquia não é o de administrar os bens mas é de auxílio ao pároco no desenvolvimento de sua função, dando critérios e modalidade de administração. A função é puramente consultiva (Cf. C. BeGUS, Diritto patrimoniale canonico. Città del Vaticano, 2018, p. 172-173; P. VALDRINI, Comunità, persona, governo. Lezioni sui i libri I e II del CIC 1983, Città del Vaticano, 2013, p. 174-176).
} 
A participação dos leigos nestes órgãos colegiados tem como fundamento a participação e corresponsabilidade do laicato no governo da Igreja em seus diferentes âmbitos, mesmo que estes conselhos tenham apenas uma função consultiva ${ }^{52}$. Outras funções como ecônomo diocesano e juiz em um tribunal colegiado são prospectivas a uma cooperação mais atuante na potestas de regime.

\subsection{O ofício do Ecônomo Diocesano}

O ofício de Administrador Financeiro Diocesano (Ecônomo) $)^{53}$ é obrigatório e é nomeado (nominetur) pelo bispo diocesano após a consulta ao colégio de consultores e ao conselho de finanças. $\mathrm{O}$ requisito é que seja perito em assuntos econômicos, notável pela sua inteira probidade ${ }^{54}$ e por ser ofício eclesiástico que seja católico ${ }^{55}$. É possível receber a nomeação um clérigo, um religioso ou um leigo. A normativa atual evita qualquer aparecimento de nepotismo no governo da diocese, mesmo que não haja proibição contra parentes próximos do bispo diocesano, seria, de qualquer forma, imprudente nomeá-lo como Ecônomo ${ }^{56}$.

Importante dizer que é um ofício estável em sede plena ou sede vacante. Tem a duração de cinco anos podendo ser renovável e a remoção é prevista somente por uma causa grave e sendo necessária uma consulta prévia ao colégio de consultores e ao conselho para assuntos econômicos ${ }^{57}$. Isso se dá em razão da garantia da oportuna

${ }^{51}$ Cf. P. VALDRINI, Comunità, persona, governo. Lezioni sui i libri I e II del CIC 1983, Città del Vaticano, 2013, p. 92.

${ }^{52}$ Cf. C. P. GARCíA. Sinodalidad y laicato. Corresponsabilidad y participación de los laicos en la vocación sinodal de la Iglesia, in Ius Canonicum, vol. 59, 2019, p. 12.

${ }^{53}$ Cf. cân. 494.

${ }^{54}$ Cf. Idem.

${ }^{55}$ Cf. cân. 149 .

${ }^{56}$ Cf. J. I. ARRIETA. De Consiglio a rebus oeconomicis et de oeconomo, in ARRIETA, J.I. (ed). Codice di Diritto Canonico e Leggi Complementari commentato. $6^{\circ}$ ed., Roma, 2018, p. 381-384.

${ }^{57}$ Cf. cân. 494 § 2. 
independência pessoal do administrador, bem como, evitar as inconveniências que comportaria pra gestão econômica uma substituição intempestiva por outra pessoa. Além disso, se o Ecônomo for eleito Administrador Diocesano na sede vacante, o Conselho Financeiro deverá nomear outro para o cargo mesmo que seja temporariamente. A função do Ecônomo diocesano é o de administrar os bens da diocese, sob a autoridade do Bispo, e com as receitas da diocese realizar as despesas autorizadas seguindo as diretivas do Conselho para assuntos econômicos ${ }^{58}$. Ele também deve apresentar ao conselho para os assuntos econômicos as contas das receitas e despesas anualmente ${ }^{59}$. O bispo diocesano também pode confiá-lo a administração dos patrimônios eclesiásticos privados de um administrador próprio ${ }^{60}$.

Com os requisitos mencionados acima, um batizado poderia livremente ser nomeado para o ofício de Ecônomo Diocesano para a administração dos bens eclesiásticos sob a autoridade do bispo diocesano e em colaboração com o Conselho para assuntos econômicos. A obrigatoriedade e instabilidade do ofício determinado pelo direito universal e particular, a vinculação direta a figura do bispo diocesano e a administração dos bens sujeitos a ele, lhe assegura, em nome do bispo, o exercício de uma potestas executiva em administrar os bens da Igreja Particular ${ }^{61}$.

\subsection{O leigo como Juiz em Tribunal colegiado}

\footnotetext{
${ }^{58}$ Cf. F. Coccopalmerio. Comentario, in. A.MArzoA - J.Miras - R.RodríGuezOCAÑA (dir.), Comentario exegético al Código de Derecho Canónico, v.II/2, Pamplona, 2002, p. 1125-1135; M.CAMPO, Ecónomo, in Diccionario General de Derecho Canónico, ed. J. OtADUY - A. ViAnA - J. SEDANO, III, Pamplona 2012, p.512-516.

${ }^{59} \mathrm{Cf}$. cân. $494 \S 3$ e 4.

${ }^{60}$ Cf. cân. 1278 .

${ }^{61}$ Cf. C. Begus, Diritto patrimoniale canonico. Città del Vaticano, 2018, p. 172173; Cf. P. VALDRINI, Comunità, persona, governo. Lezioni sui i libri I e II del CIC 1983, Città del Vaticano, 2013, p. 81-83.
} 
A função judicial, enquanto parte da potestas de jurisdição, consiste no ius dicere ou no declarar o direito nas situações controvérsias. Também se conceitua a potestas judicial eclesiástica como aquela potestas pública de governo mediante o qual se definem os direitos controversos e se declaram autoritativamente os direitos violados sob a imposição de sanções. E como parte da potestas pessoal e plena de governo, a potestas judiciária pertence de modo próprio aos órgãos hierárquicos capitais (Romano Pontífice e bispos). Na diocese, o bispo exerce o poder judicial pessoalmente ou por meio de outros ${ }^{62}$. Contudo, o poder judicial também pode ser exercitado em modo vigário por meio de ofícios e estruturas estavelmente constituídas (tribunais) por um determinado âmbito territorial ou pessoal (âmbito de competência) $)^{63}$. Já o vigário judicial e os juízes exercem o poder judicial em virtude do ofício. E sobre a delegação, a potestas judiciária não pode ser delegada, exceto para certos atos preliminares, como a designação de um auditor para instruir um caso $^{64}$.

Com o Concílio Vaticano II e a nova normativa canônica de $1983^{65}$, os leigos por sua vez, podem receber o ofício de juiz, seja para exercitá-lo como membro de um colégio junto aos clérigos, seja, sobretudo, para exercitá-lo como juiz instrutor ou auditor ${ }^{66}$. A necessidade para a concessão da permissão, na realidade, se dá em razão da insuficiência de clérigos nas dioceses ou que estes não atendam os requisitos necessários para a função. Não seria pela conveniência, comodidade, oportunidade ou utilidade aponta Ortega, pois a existência do juiz leigo não está prevista para circunstâncias ordinárias, mas extraordinárias ${ }^{67}$.

${ }^{62}$ Cf. cân. $391 \S 2$ (IoANnes PAUlus PP. II, Codex Iuris Canonici, auctoritate Ioannis Pauli PP. II promulgatus, in $A A S$, LXXV (1983), Pars II, 1-320).

${ }^{63}$ Cf. M.J. Arroba Conde, Diritto Processuale Canonico. $6^{\circ}$.ed., Roma, p. 94.

${ }^{64}$ Cf. cân. $1428 \S 1$.

${ }^{65}$ Cf. E.MALUMBRES, Los laicos y la potestad de regimen en los trabajos de reforma codicial: una cuestion controvertida, in Ius Canonicum, vol. 26, 1986, p. 563-625.

${ }^{66}$ Como membro de um colégio junto aos clérigos cf. cân. $1428 \S 2$. 
Os leigos, dessa forma, gozam da potestas judicial e, por isso, segundo Arroba, não se justifica uma potestas delegada, ou a noção de um juiz extraordinário, ou a função de cooperador atribuída a potestas judiciária exercitada por um leigo. Trata-se de uma potestas que não se exerce de modo autônomo, mas em cooperação com ao menos dois clérigos, o que não se permite de qualificar a potestas judiciária de um leigo como secundária ${ }^{68}$.

Dessa forma, do ponto de vista processual, a diferença entre habiles sunt e cooperari possunt é irrelevante. No caso da função decisiva, a potestas do juiz leigo é de natureza integrativa, ao ser exercida no colégio. No caso da função judicial do Instrutor (que pode ser um leigo), as suas decisões, sendo pessoais, tem valor vinculante. Em todos os casos, o exercício de cooperação da potestas pressupõe que o leigo possua uma verdadeira potestas jurídica, na verdade, qualquer juiz coopera com o juiz próprio ${ }^{69}$.

Em suma, os leigos, homens ou mulheres, podem ser nomeados juízes diocesanos ${ }^{70}$. Para nomeação de um chistifideles laici é necessário a permissão da conferência episcopal. Tal permissão pode ser concedida na modalidade estabelecida pela mesma conferência episcopal. A normativa canônica não exige requisitos pessoais aos juízes leigos que coincidam com as do clérigo nos títulos e na virtude subjetiva e objetiva. O juiz diocesano leigo pode exercitar o seu ofício só como integrante de um colégio ${ }^{71}$. Não podem, assim, ser confiado ao juiz leigo as causas que decide um juiz único. $\mathrm{E}$ a permissão da conferência

\footnotetext{
${ }^{67}$ M.E.O. ORTEGA, Juez Laico, In Diccionario General de Derecho Canónico, ed. J. OtADUY - A. VIANA - J. SEDANO, IV, Pamplona 2012, p.896-900.

${ }^{68}$ Cf. M.J. Arroba Conde, Diritto Processuale Canonico. $6^{\circ}$.ed., Roma, nota 43.

${ }^{69}$ Cf. Ibid., p. 95.

${ }^{70}$ Cf. Z. GROCHOLEWSKI. Comentario In. A.MARZOA - J.MiRAS - R.RodRÍGUEZOCAÑA (dir.), Comentario exegético al Código de Derecho Canónico, v.IV/1, Pamplona, 2002, p. 482-786.

${ }^{71}$ Cf. cân. $1421 \S 2$; PONTIFICIUM CONSILIUM DE LEGUM TEXTIBUS, Instructio servanda a Tribunalibus diœecesanis et interdiœecesanis in pertractandis Causis nullitatis Matrimonii: Dignitas Connubii, in Communicationes, XXXVII (2005), 11-92, art. $43 \S 2$.
} 
episcopal para a inserção de um juiz leigo para integrar o colégio deve ser sugerida pela necessidade. Somente um dos juízes do colégio pode ser leigo, seja este formado por três ou por cinco membros. O requisito de necessidade é amplo quando se leva em conta as qualidades e competências técnicas, além dos títulos que são exigidos para o ofício de juiz diocesano nem sempre presentes nos clérigos $^{72}$.

\subsection{Outras funções exercidas por leigo em um Tribunal}

Pode-se afirmar que o Ofício eclesiástico é qualquer cargo estavelmente constituído por disposição divina ou eclesiástica que deve ser exercido para um fim espiritual. As obrigações e os direitos próprios de cada ofício eclesiástico se determinam pelo direito pelo qual se constitui o ofício ou por decreto da autoridade competente ${ }^{73}$.

Os leigos, que forem julgados idôneos, têm capacidade de assumir ofícios eclesiásticos e outros cargos confiados pela autoridade eclesiástica conforme as prescrições do direito. Os leigos dotados da ciência devida, prudência e honestidade têm capacidade para prestar auxílio como peritos ou conselheiros competentes ${ }^{74}$. Além da possibilidade de cooperação na potestas de jurisdição como juiz de um tribunal colegiado, são muitas as funções que lhe podem ser atribuídas segundo as normas prescritas. Podem ser elencadas as seguintes funções: $\operatorname{assessor}^{75}$, auditor ${ }^{76}$, relator ou ponens ${ }^{77}$, promotor de justiça e defensor do vínculo ${ }^{78}$, notário $^{79}$, peritos ${ }^{80}$, intérprete ${ }^{81}$, advogado e procurador ${ }^{82}$.

\footnotetext{
${ }^{72}$ Cf. M.J. ARroba Conde, Diritto Processuale Canonico. $6^{\circ}$.ed., Roma, p. 207-208.

${ }^{73}$ Cf. cân. 145 .

${ }^{74}$ Cf. cân. 228.

${ }^{75}$ Cf. cân. 1424 .

${ }^{76}$ Cf. cân. 1428 .

${ }^{77}$ Cf. cân. 1429 .

${ }^{78} \mathrm{Cf}$. cânn. 1430 - 1435 .

${ }^{79}$ Cf. cânn. 1437; 482-483.

${ }^{80} \mathrm{Cf}$. cânn. 1574 - 1581.

${ }^{81} \mathrm{Cf}$. cân. 1471 .

${ }^{82}$ Cf. cân. 1483 .
} 


\section{Conclusão}

Assim sendo, percebe-se que é possível uma participação ativa dos leigos no governo da Igreja segundo as normas já prescritas na legislação canônica atual. $\mathrm{O}$ escopo do presente texto foi $\mathrm{o}$ de evidenciar esta possibilidade de cooperação laical no poder de regime tendo como base a normativa de 1983 que fornece parâmetros para isso.

Diante disso, se faz urgente avançar ainda mais na cooperação efetiva e responsável dos fieis leigos no governo da Igreja em muitas de suas esferas. Seria uma atitude retrógrada limitar-se a conselhos, colégios ou até outros meios para uma simples expressão de opinião esporádica ou ocasional sobre algumas matérias. Faz-se necessário superar o clericalismo ainda presente. É preciso reforçar ainda mais os meios de comunicação e de decisão em todas as comunidades. É preciso uma colaboração ainda mais eficiente e de modo estável naqueles órgãos e estruturas de governo de cooperação nos diversos níveis e inclusive na Cúria Romana ${ }^{83}$ para uma Igreja com leigos mais atuantes e responsáveis em seu governo e organização.

\footnotetext{
${ }^{83} \mathrm{O}$ presente texto limitou-se às estruturas da diocese e da paróquia. Para o âmbito de Igreja Universal, a Cúria Romana neste caso, necessitaria um um outro estudo mais aprofundado e específico. Contudo, é importante dizer que recentemente, houve relevantes nomeações de fiéis leigos como membros de dicastérios romanos para cargos de responsabilidade como por exemplo no Dicastério para o Serviço do Desenvolvimento Humano Integral, em cuja regulamentação se prevê que o Secretário e o Sub-secretário podem ser leigo. Também para o Dicastério para os Leigos, Família e Vida, no qual há exigência que haja ao menos dois subsecretários leigos; o Dicastério para a Comunicação que tem a frente um Prefeito leigo, o Sr. Paolo Ruffini; na Secretaria de Estado, houve a nomeção da Sra. Francesca Di Giovanni como Subsecretária da Seção para as relações com os Estados. Importante ressaltar a participação de leigos como membros no Conselho para a Economia, na Pontificia Comissão para a Proteção de Menores, na Pontificia Comissão de Estudo e Guia para os Assuntos Econômicos e Administrativos e no Istituto para as Obras de Religião (IOR) e outros (Fonte: http://www.vatican.va/roman_curia/secretariat_state/diplomaziamultilaterale/index_onu it.htm in 13/04/2020).
} 


\section{Referência bibliográfica}

Arrieta, J.I. De Consiglio a rebus oeconomicis et de oeconomo, in Arrieta, J.I. (ed). Codice di Diritto Canonico e Leggi Complementari commentato. $6^{\circ}$ ed., Roma, 2018, p. 381-384.

Arroba Conde, M.J. Diritto Processuale Canonico. $6^{\circ}$.ed., Roma.

Begus, C., Diritto patrimoniale canonico. Città del Vaticano, 2018.

Benedictus PP XVI, Apertura del convegno pastorale della diocesi di Roma sul tema: Appartenenza ecclesiale e corresponsabilità pastorale Basilica di San Giovanni In Laterano, Martedì, 26 maggio 2009) in http://www.vatican.va/content/benedict-xvi/it/speeches/2009/may/doc uments/hf ben-xvi spe 20090526 convegno-diocesi-rm.html.

Coccopalmerio, F. Comentario, in. A.Marzoa - J.Miras - R.RodríguezOcaña (dir.), Comentario exegético al Código de Derecho Canónico, v. II/2, Pamplona, 2002, p. 1125-1135.

Concilium Oecumenicum Vaticanum II, Constitutio dogmatica de Ecclesia: Lumen Gentium, in AAS, LVII (1965), 5-71.

Concilium Oecumenicum Vaticanum II, Decretum de pastorali Episcoporum munere in Ecclesia: Christus Dominus, in AAS, LVIII (1966), 673-701.

Concilium Oecumenicum Vaticanum II, Decretum de Presbyterorum ministerio et vita: Presbyterorum Ordinis, in AAS, LVIII (1966), 9911024.

Congregatio pro Clericis et aliæ, Instructio interdicasterialis de quibusdam quæstionibus circa fidelium laicorum cooperationem sacerdotum ministerium spectantem: Ecclesice de mysterio, in $A A S$, LXXXIX (1997), 852-877.

D'Arienzo, M. Il concetto giuridico di responsabilità: rilevanza e funzione nel Diritto Canonico, Diritto e Religione, n. 24, Cosenza, 212, p. 177. 
García, C.P. Sinodalidad y laicato. Corresponsabilidad y participación de los laicos en la vocación sinodal de la Iglesia, in Ius Canonicum, vol. 59, 2019, p. 1-35.

Grocholewski, Z. Comentario, in. A.Marzoa - J.Miras - R.RodríguezOcaña (dir.), Comentario exegético al Código de Derecho Canónico, v.IV/1, Pamplona, 2002, p. 482-786.

Ioannes Paulus PP. II, Adhortatio apostolica postsynodalis: Christifideles Laici, in AAS, LXXXI (1989), 393-521.

Ioannes Paulus PP. II, Codex Iuris Canonici, auctoritate Ioannis Pauli PP. II promulgatus, in $A A S$, LXXV (1983), Pars II, 1-320.

Ioannes Paulus PP. II, Constitutio apostolica de Romana Curia: Pastor Bonus, in AAS, LXXX (1988), 841-934.

Kouveglo, E. I fedeli laici e l'esercizio della potestà nella Chiesa. Status quaestionis e ricerca di una chiave funzionale di lettura, in Apolinaris LXXXX, 1, Città del Vaticano, 2017, p. 222-223.

Malumbres, E. Los laicos y la potestad de regimen en los trabajos de reforma codicial: una cuestion controvertida, in Ius Canonicum, vol. 26, 1986, p. 563-625.

Montan, A. Collegialità e sinodalità nella vita della Chiesa: aspetti giuridici con riferimento alla Chiesa Particolare, in. Aa.V.v., Il governo nel servizio della comunione ecclesiale, Quaderno della Mendola 25, Milano, 2016, p. 31-58.

Montan, A. Ministeria, munera, officia. I laici titolari di uffici e di ministeri (cann. 228, 230, 274): precisazioni terminologiche, in. Aa.V.v., Il governo nel servizio della comunione ecclesiale, Quaderno della Mendola 8, Milano, 2000.

Montan, A. Responsabilità ecclesiale, corresponsabilità e rappresentanza, in P. Gherri (a cura di) Responsabilità ecclesiale, corresponsabilità e rappresentanza: atti della giornata canonistica interdisciplinare, Città di Vaticano, 2010. 
Ortega, M.E.O. Juez Laico, in Diccionario General de Derecho Canónico, ed. J. Otaduy - A. Viana - J. Sedano, IV, Pamplona 2012, p.896-900.

Paulus PP. VI, Litteræ apostolicæ motu proprio datæ quo normæ ad quædam exsequenda Ss. Concilii Vaticani II Decreta statuuntur: Ecclesice Sanctoe, in AAS, LIIX (1966), 757-787.

Paulus PP. VI, Litteræ apostolicæ motu proprio datæ quo normæ ad quædam exsequenda Ss. Concilii Vaticani II Decreta statuuntur: Ecclesice Sanctoe, in AAS, LIIX (1966), 757-787.

Pontificium Consilium de Legum Textibus, Instructio servanda a Tribunalibus diœecesanis et interdiœcesanis in pertractandis Causis nullitatis Matrimonii: Dignitas Connubii, in Communicationes, XXXVII (2005), 11-92.

Valdrini, P. Comunità, persona, governo. Lezioni sui i libri I e II del CIC 1983, Città del Vaticano, 2013.

Valdrini, P. Fedele, uguaglianza e organizzazione della Chiesa nel CIC del 1983, in A. Sabetta (cur.), Studi di Diritto canonico in onore di S. E. Mons. Ignazio Sanna, Roma, 2012.

Viana, A. El gobierno colegial en la Iglesia, in Ius Canonicum 36, 1996, p.465-499.

Viana, A. El problema de la participación de los laicos en la potestad de régimen. Dos vías de solución, in Ius Canonicum, vol 54, 2014, p. 603-638.

Zuanazzi, I. La corresponsabilità dei fedeli laici nel governo ecclesiale, in. Aa.V.v., Il governo nel servizio della comunione ecclesiale, Quaderno della Mendola, 25, Milano, 2016, p. 101-148.

\section{Referência para consulta eletrônica}

https://www.vaticannews.va/pt/vaticano/news/2020-01/secretariaestado-nomeacao-mulher.html in 13/04/2020. 
http://www.vatican.va/roman_curia/secretariat_state/diplomaziamultilaterale/index_onu it.htm in 13/04/2020.

http://www.humandevelopment.va/it/il-dicastero/statuto.html in 13/04/2020.

http://www.laityfamilylife.va/content/laityfamilylife/pt/il-dicastero/lostatuto.html in 13/04/2020.

http://www.vatican.va/roman_curia/uffici/consiglio-economia/ documents/consiglio-per-economia_profilo it.html in 13/04/2020. http://www.protectionofminors.va/content/tuteladeiminori/it/sezionechi_siamo/pagina-membri_new.html in 13/04/2020. http://www.ior.va/content/ior/it/governance.html in 13/04/2020. 